\title{
Control of Peptide Aggregation and Fibrillation by Physical PEGylation
}

\section{Ambrosio, Elena}

2018-10

Ambrosio , E , Podmore , A , dos Santos, A L G , Magarkar, A, Bunker , A, Caliceti , P , Mastrotto , F , van der Walle , C F \& Salmaso , S 2018, ' Control of Peptide Aggregation and Fibrillation by Physical PEGylation ', Biomacromolecules, vol. 19 , no. 10 , pp. 3958-3969 . https://doi.org/10.1021/acs.biomac.8b00887

http://hdl.handle.net/10138/326464

https://doi.org/10.1021/acs.biomac.8b00887

unspecified

acceptedVersion

Downloaded from Helda, University of Helsinki institutional repository.

This is an electronic reprint of the original article.

This reprint may differ from the original in pagination and typographic detail.

Please cite the original version. 


\section{Control of peptide aggregation and fibrillation by}

\section{physical PEGylation}

Elena Ambrosio $^{a}$, Adrian Podmore $^{b}$, Ana L Gomes dos Santos ${ }^{b}$, Aniket Magarkar $^{c}$, Alex

Bunker $^{c}$, Paolo Caliceti $^{a}$, Francesca Mastrotto $^{a}$, Christopher F. van der Walle $^{b}$, Stefano Salmaso $a^{a^{*}}$

${ }^{a}$ Department of Pharmaceutical and Pharmacological Sciences, Università degli Studi di Padova, via F. Marzolo 5, 35131 Padova, Italy.

${ }^{\mathrm{b}}$ MedImmune Ltd., Formulation Sciences, Granta Park, Cambridge, CB21 6GH, UK.

${ }^{c}$ Centre for Drug Research, Faculty of Pharmacy, University of Helsinki , P.O. Box 56, FI00014, Finland

* author for correspondence: stefano.salmaso@unipd.it 


\section{ABSTRACT}

Peptide therapeutics have the potential to self-associate, leading to aggregation and fibrillation. Non-covalent PEGylation offers a strategy to improve their physical stability; an understanding of the behaviour of the resulting polymer:peptide complexes is, however, required. In this study we have performed a set of experiment with additional mechanistic insight provided by in silico simulations to characterise the molecular organisation of these complexes. We used palmitoylated vasoactive intestinal peptide (VIP-palm) stabilized by methoxy-poly(ethylene glycol) $5 \mathrm{kDa}$-cholane (PEG-cholane) as our model system. Homogeneous supramolecular assemblies were found only when complexes of PEGcholane:VIP-palm exceeded a molar ratio of $2: 1$; at and above this ratio the simulations showed minimal exposure of VIP-palm to the solvent. Supra-molecular assemblies formed, composed of, on average, 9-11 PEG-cholane:VIP-palm complexes with 2:1 stoichiometry. Our in silico results showed the structural content of helical conformation in VIP-palm increases when it is complexed with the PEG-cholane molecule; this behaviour becomes yet more pronounced when these complexes assemble into larger supra-molecular assemblies. Our experimental results support this: the extent to which VIP-palm loses helical structure as a result of thermal denaturation was inversely related to the PEG-cholane:VIP-palm molar ratio. The addition of divalent buffer species and increasing the ionic strength of the solution both accelerate the formation of VIP-palm fibrils, which was partially and fully suppressed by 2 and $>4$ mole equivalents of PEG-cholane, respectively. We conclude that the relative freedom of the VIP-palm backbone to adopt non-helical conformations is a key step in the aggregation pathway.

Keywords: biopharmaceuticals, formulation, in silico modelling, excipient, poly(ethylene glycol), cholanic acid, vasoactive intestinal peptide 


\section{INTRODUCTION}

The number of protein and peptide based drug therapies (biopharmaceuticals), particularly monoclonal antibodies, has increased markedly over the last 20 years; a considerable number of peptide therapeutics have already been approved by the US Food and Drug Administration, with around 140 candidates are currently in clinical trials. ${ }^{1,2}$ In comparison to small drug molecules, peptide therapeutics offer the advantage of high bioselectivity and are often targeted to metabolic diseases. Their development, however, is often hampered by their physical, chemical and enzymatic instability in addition to rapid clearance and low bioavailability. ${ }^{3}$ Biopharmaceutical products usually require at least 18-24 months shelf-life, which can be challenging to achieve. ${ }^{4}$ For example, recombinant human (rh) interferon (INF) $\beta-1 b$ and $\alpha-2 b$, some monoclonal antibodies (mAbs), rh growth hormone (rhGH) and rh insulin, undergo spontaneous denaturation and degradation if downstream processing, formulation, shipping and storage are not properly optimized. ${ }^{5}$ Protein structural instability often yields increased $\beta$-sheet content leading to amorphous or fibrillar aggregates, ${ }^{6}$ with consequent reduction in activity, bioavailability and, in the worst case, increased toxicity. ${ }^{7,8}$

Protein and peptide structural rearrangement into ordered 3-dimensional fibrils ${ }^{9,10}$ has been observed in vitro and in vivo, the latter being etiologically correlated to the development and progression of neurodegenerative diseases including Alzheimer's and Parkinson's diseases. ${ }^{11,}$ 12

Strategies developed to enhance the stability of proteinaceous drugs include chemical modifications either by genetic manipulation of the protein sequence ${ }^{13}$ or by post-translation manipulation including lipidation, glycosylation or chemical (covalent) conjugation with hydrophilic polymers such as poly(ethylene glycol) (PEG). ${ }^{14,}{ }^{15}$ Nevertheless, these strategies may reduce activity of the peptide therapeutic or worsen its physico-chemical properties for downstream processing, formulation and delivery. ${ }^{16}$ 
Achieving the desired shelf-life of a peptide/protein with poor physico-chemical stability can be achieved with judicious selection of excipients such as amino acids, sugars, buffer/pH and ionic strength. ${ }^{17,18}$ Additionally, non-ionic surfactants are added to prevent surface adsorption-induced denaturation and concomitant aggregation, although these can themselves occasionally bind proteins in the unfolded state. ${ }^{6}$ Self-assembling amphiphilic macromolecules are known to physically associate with several therapeutic proteins via electrostatic and/or hydrophobic interactions. ${ }^{19,20}$ This phenomenon has been exploited in the design of amphiphilic polymers (methoxy-PEGs bearing a terminal cholanic moiety) to formulate rhGH for improved pharmacokinetics and pharmacodynamics. ${ }^{21,22}$

This gives rise to the principle of non-covalent (physical) PEGylation of lipidated peptides, in which the hydrophobic moiety of the amphiphilic polymer is anticipated to interact with the acyl chain, leaving the PEG moiety aqueously solvated. Note that lipidation is not employed to solely facilitate physical PEGylation of the peptide but as a common strategy to increase the in vivo half-life of therapeutic peptides via binding to the hydrophobic pockets of human serum albumin (HSA), examples being liraglutide and detemir. ${ }^{23}$ Physical PEGylation can have advantages over chemical PEGylation where covalent conjugation of the peptide therapeutic attenuates target binding affinity through steric inhibition and/or associated structural changes. ${ }^{24}$ Furthermore, physical PEGylation can circumvent the need for additional, possibly complex chemistry, or the introduction of amino acids conducive to conjugation (e.g. lysine). ${ }^{25}$

A recent study has also highlighted that lipidation can accelerate the formation of peptide fibrils in bulk solution, at least for insulin under acidic conditions and elevated temperatures. ${ }^{26}$ This is interesting since our previous work with a palmitoylated vasoactive intestinal peptide mutant ('VIP-palm') observed that the gelation of concentrated samples was induced by acidic conditions in the absence of methoxy-PEG5kDa-cholane ('PEG- 
cholane'). ${ }^{27}$ Since gelation of concentrated peptide solutions is generally indicative of the presence of peptide fibrils, the mechanism by which physical PEGylation apparently attenuates the aggregation/fibrillation process is worthy of further study. Fibrillation is a multi-step process of amyloidogenic peptides that is usually defined by a sigmoidal kinetic: a 'lag' phase preceding a steep transition zone, the 'elongation' phase, followed by the 'plateau' phase. During the lag phase, the peptide undergoes structural alteration with an increase in $\beta$-structure and formation of ordered clusters ${ }^{28}$ that nucleate elongated fibrils without ramification (primary fibrillation) and the branching of fibrils (secondary fibrillation). Fibrillation can affect peptide bioavailability, efficacy and toxicity. ${ }^{29,30}$

In the context of formulation, excipient (PEG-cholane) control of VIP-palm aggregation/fibrillation is not only relevant to its development as a potential therapeutic ${ }^{31-33}$ but also to the structurally related glucagon/secretin superfamily, which includes lipidated peptide drugs in the clinic, e.g. semaglutide, liraglutide. Thus, this work aims to elucidate at the molecular level how the amphiphilic polymer PEG-cholane forms well-defined assemblies with VIP-palm that can inhibit its aggregation and fibrillation. An understanding of the aggregation behaviour of the supramolecular assemblies will be derived from a combination of in silico modelling and analytical data, and will refer to previous data ${ }^{27}$ showing that PEG-cholane bound VIP-palm with a 2:1 molar ratio at the acyl chain (K $\sim 3.5 \times 10^{4} \mathrm{M}^{-1}$ ), increasing aqueous solubility (5000-fold at $\mathrm{pH} 7.4$ ) and stability under accelerated storage $\left(25{ }^{\circ} \mathrm{C}, 30 \mathrm{~d}\right)$, recovering $\alpha$-helical conformation at $\mathrm{pH} 7.4$, and significantly prolonging peptide concentration in the rat systemic circulation $(0.1 \mathrm{mg} / \mathrm{kg}$, subcutaneous administration). A molecular model of this PEG-cholane:VIP-palm assembly will provide insight to the ordered aggregation of peptides and a basis from which to exploit PEG-cholane as a multi-functional excipient for the formulation of lipidated peptide therapeutics. 


\section{MATERIALS AND METHODS}

VIP harbouring the substitution of Trp for Ser 25 and palmitoylated via an amide linkage to the side chain of lysine $20\left(\mathrm{H}_{2} \mathrm{~N}-\mathrm{HSDAVFTDNYTRLRKQMAV-K}(\mathrm{Palm})-\mathrm{KYLNWILN}-\right.$ CO-NH 2 ), termed 'VIP-palm', was synthesized by solid phase peptide synthesis (CPC Inc., Sunnyvale, CA, USA). Cholane conjugated to $5 \mathrm{kDa}$ methoxy-polyethylene glycol, termed 'PEG-cholane', was synthesized according to a method reported elsewhere. ${ }^{21}$

\section{Asymmetrical Flow Field Flow Fractionation}

VIP-palm and PEG-cholane:VIP-palm solutions in $5 \mathrm{mM}$ sodium acetate buffer, $\mathrm{pH}$ 5.0, or $5 \mathrm{mM}$ sodium acetate buffer, $140 \mathrm{mM} \mathrm{NaCl}, \mathrm{pH} 5.0$, were prepared by adding $80 \mu \mathrm{L}$ of $10 \mathrm{mg} / \mathrm{mL}$ VIP-palm stock solution to $320 \mu \mathrm{L}$ of buffer or to $320 \mu \mathrm{L}$ of PEG-cholane solutions in order to yield $2 \mathrm{mg} / \mathrm{mL}$ VIP-palm and 0:1-6:1 PEG-cholane:VIP-palm molar ratios. PEG-cholane:VIP-palm samples were also prepared using $20 \mathrm{mM}$ sodium phosphate, $140 \mathrm{mM} \mathrm{NaCl}$ buffer, $\mathrm{pH} 7.4$ in place of the acetate buffer.

The samples were analysed using a Wyatt Eclipse AF4 instrument (Santa Barbara, CA, USA), equipped with a Superon PES membrane (MWCO $1 \mathrm{kDa}$ ), an Dual Tech Eclipse Separation System, a Wyatt Dawn Heleos-II light scattering detector, a Wyatt Optilab T-Rex IR detector. Two Agilent 1100 series pumps ran the system at a $2 \mathrm{~mL} / \mathrm{min}$ cross-flow at the separation membrane. Five $\mu \mathrm{L}$ of each sample were injected immediately after generation in the system that was equilibrated at $25{ }^{\circ} \mathrm{C}$ with the same buffer of the sample. The results were analysed with an Agilent Chemstation and Astra 6.1 software. A Debye plot $\left(\mathrm{K}^{*} \mathrm{c} / \mathrm{R}(\Theta)\right.$ plotted against $\sin 2(\Theta / 2)$, where $\mathrm{c}=$ concentration, $\Theta=$ scattering angle, $\mathrm{K}=$ optical constant, $\mathrm{R}(\Theta)$ = Rayleigh ratio) using Zimm formalism was produced for each data collection point in a defined region of the chromatogram (the elution peak) and the values (intercept and slope) averaged to evaluate mass. 


\section{Simulation of VIP-palm:PEG-cholane association}

Peptide model. The initial structure for the VIP-palm was obtained from the available NMR structure in the PDB database: ${ }^{34} \mathrm{PDB}$ id:2RRH. ${ }^{35}$ The peptide structure was then edited using UCSF Chimera. ${ }^{36}$ The obtained VIP(Trp25) peptide structure was then palmitoylated using the CHARMM-GUI server. ${ }^{37}$ The OPLS-AA forcefield parameter set was used to simulate VIP-palm. The protonation state for the peptide at $\mathrm{pH} 5$ was obtained using the pdb2gmx tool, found in Gromacs. ${ }^{38}$

Polymer model. The EG-cholane model was built using the OPLS-AA parameter set. We used models developed in previous studies for the $5 \mathrm{kDa}$ PEG-segment $\mathrm{t}^{39,40}$ and the model of the cholane group was built from our model of cholesterol used in previous studies. ${ }^{41,42}$ MD Simulation and parameters. In total, 10 systems were simulated as shown in Table S2. All systems were simulated for $0.6 \mu$ s, with the exception of systems 9 and 10; for these systems, the first $100 \mathrm{~ns}$ were considered as equilibration time. Due to the large simulation system size, for the case of systems 9 and 10, simulations were performed for $1 \mu$ s and first $0.5 \mu \mathrm{s}$ was considered as equilibration time; thus all analyses were performed on the final 0.5 $\mu$ s of the simulation run.

The molecular dynamics simulations were conducted under constant pressure (1 Bar) conditions, controlled through a Parrinello-Rahman barostat ${ }^{43}$ using a semi-isotropic pressure scheme. The temperature $(310 \mathrm{~K})$ was controlled using the Nose-Hoover thermostat. ${ }^{44}$ The temperatures of the solute and solvent were controlled independently. For water we used the TIP3 water model. ${ }^{45}$ Periodic boundary conditions with the usual minimum image convention were used in all three directions. In order to preserve the covalent bond lengths, the linear constraint solver (LINCS) algorithm ${ }^{46}$ was employed and a 2 fs time step was used in all simulations. The Lennard-Jones Interactions were cut off at $1.0 \mathrm{~nm}$, for the electrostatic 
interactions we employed the particle mesh Ewald method. ${ }^{47}$ All error bars were calculated using the block method. ${ }^{48}$ All simulations were performed with Gromacs software $4.6 .7^{38}$ and all visualizations were performed using VMD software. ${ }^{49}$ All analysis was performed using the standard analysis tools available in Gromacs as well as previously developed in-house protocols (for solvent accessible surface area analysis). ${ }^{50}$

\section{Dynamic Light Scattering}

VIP-palm alone and PEG-cholane:VIP-palm molar ratios of 2:1, 4:1, 6:1 (2 mg/mL VIPpalm) were prepared in $5 \mathrm{mM}$ sodium acetate buffer, $\mathrm{pH} 5.0$, or in $5 \mathrm{mM}$ sodium succinate buffer at $\mathrm{pH} 5.0$, or the same buffers with $140 \mathrm{mM} \mathrm{NaCl}$. Samples were analysed by Dynamic Light Scattering (DLS) using a Malvern Zetasizer Nano S Photon Correlation Spectrometer. The samples were equilibrated at $25{ }^{\circ} \mathrm{C}$ for 300 seconds before analyses. The size of the complexes was derived as number, volume and intensity. Since the particles measured were $<<300 \mathrm{~nm}$, volume and number distributions were calculated from the intensity distribution assuming a population of spherical, isotropic particles, this was considered reasonable since the incubation time and temperature excluded the generation of fibrils in the samples.

\section{Circular Dichroism}

VIP-palm alone and PEG-cholane:VIP-palm molar ratios of 2:1, 4:1, 6:1 (13.6 $\mu \mathrm{M}$ VIPpalm) were prepared in $5 \mathrm{mM}$ sodium phosphate buffer, $140 \mathrm{mM} \mathrm{NaF}, \mathrm{pH}$ 5.0. Samples were analysed by Circular Dichroism (CD) in the far UV (195-260 nm) in the temperature range 25 to $85^{\circ} \mathrm{C}$ and back to $25{ }^{\circ} \mathrm{C}$ at $1{ }^{\circ} \mathrm{C} / \mathrm{min}$ step increase, using a J-810 Jasco spectropolarimeter (Tokyo, Japan) and a quartz cuvette with $0.1 \mathrm{~cm}$ path-length. The average of three accumulations was elaborated for data analysis. The CD spectra of free VIP-palm 
and of the PEG-cholane:VIP-palm complexes were background corrected for signal generated by the buffer or the PEG-cholane solutions. The CD spectra were plotted as molar circular dichroism $(\Delta \varepsilon)\left(\mathrm{L} \cdot \mathrm{mol}^{-1} \cdot \mathrm{cm}^{-1}\right) v s$ wavelength and the secondary structure content of the VIP-palm was calculated using 'CDNN' software by Gerald Böhm. The VIP-palm melting temperature was obtained by the molar ellipticity at $222 \mathrm{~nm} v s$ temperature plot. $^{51}$ $\mathrm{NaF}$ was used in place of $\mathrm{NaCl}$ since the latter absorbs light in the far $\mathrm{UV}$ region thus interfering with the CD signal. ${ }^{52}$

\section{Fibrillation studies}

VIP-palm alone $(0.5,1$ or $2 \mathrm{mg} / \mathrm{mL})$ and PEG-cholane:VIP-palm at molar ratios of 2:1, 4:1 and $6.1(2 \mathrm{mg} / \mathrm{mL}$ VIP-palm) were prepared in $5 \mathrm{mM}$ sodium succinate buffer at $\mathrm{pH} 5.0$ and 7.4 , or $5 \mathrm{mM}$ sodium acetate at $\mathrm{pH} 5.0$ and 7.4 , with and without $140 \mathrm{mM} \mathrm{NaCl}$, or $5 \mathrm{mM}$ sodium phosphate, $140 \mathrm{mM} \mathrm{NaCl}, \mathrm{pH} 7.4$, for the fibrillation assay by adding $0.16 \mathrm{mg} / \mathrm{mL}$ Thioflavin $\mathrm{T}(\mathrm{ThT})$ solution in deionized water to yield a $50 \mu \mathrm{M}$ ThT final concentration. ${ }^{53-55}$ The samples $(200 \mu \mathrm{L})$ were placed in a Corning 96-well half bottom plate (Corning 3381, Flintshire, United Kingdom), sealed with a Costar aluminium foil and incubated at 25, 37 and $50{ }^{\circ} \mathrm{C}$, without agitation. Every 35 minutes for 92 hours the samples underwent fluorescence analysis using a Viktor X3 (Perkin Elmer Italia - MI) plate reader ( $\left.\lambda_{\mathrm{ex}} 440 \mathrm{~nm}, \lambda_{\mathrm{em}} 480 \mathrm{~nm}\right)$. The data were analysed using WorkOut 2.5 and GraphPad Prism 4.0 software, applying least squares fitting method and the following equation to derive the fibrillation 'lag time':

$$
\mathrm{Y}=\mathrm{y}_{0}+\mathrm{yf} /\left(1+\exp \left(-\left(\mathrm{t}-\mathrm{t}_{0}\right) * \mathrm{~K}\right)\right)
$$

where $\mathrm{Y}$ is the detected fluorescence, $\mathrm{y}_{0}$ is the fluorescence at time $0, \mathrm{~K}$ is the apparent rate constant for the growth of fibril corresponding to $1 / \tau \cdot{ }^{56}$ The lag time was derived from $t_{0}$ and $\mathrm{K}$ as follows:

Lag time $=\mathrm{t}_{0}-(2 / \mathrm{K})=\mathrm{t} 0-2 \tau$ 


\section{Transmission Electron Microscopy (TEM)}

VIP-palm and PEG-cholane:VIP-palm at molar ratios of 2:1, 4:1, 6:1 (2 mg/mL VIP-palm) were prepared in $5 \mathrm{mM}$ sodium acetate, with and without $140 \mathrm{mM} \mathrm{NaCl}$ buffer or in $5 \mathrm{mM}$ succinate buffer, with and without $140 \mathrm{mM} \mathrm{NaCl}, \mathrm{pH}$ 5.0. The samples were incubated for 67 $\mathrm{h}$ at $37^{\circ} \mathrm{C}$, without agitation and then transferred on copper grids (400 mesh), stained with a $1 \% \mathrm{w} / \mathrm{v}$ uranyl acetate solution and covered with a punctate carbon layer. The samples were analysed by TEM in negative staining mode using a Tecnai G2 microscope (FEI).

\section{RESULTS AND DISCUSSION}

Excess polymer drives ordered, homogenous supramolecular assemblies that retain peptide stability

DLS was performed to assess the hydrodynamic diameter ('size') of VIP-palm complexed with PEG-cholane, under different conditions of buffer, $\mathrm{pH}$, ionic strength and molar ratios. Succinate, phosphate and acetate salts were chosen to buffer from the neutral to mildly acidic $\mathrm{pH}$ range, with and without $140 \mathrm{mM} \mathrm{NaCl}$ to investigate the effect of ionic strength. Due to poor solubility, VIP-palm was analysed at pH 5.0, while PEG-cholane:VIP-palm molar ratios of 2:1, 4:1 and 6:1 were analysed at $\mathrm{pH} 5.0$ and 7.4. Figure 1 shows that free VIP-palm in low ionic strength buffer, $\mathrm{pH} 5$, self-assembled into small colloidal particles ca. 3-4 nm in diameter. The size of the peptide colloids increased to $c a .7-8 \mathrm{~nm}$ when $140 \mathrm{mM} \mathrm{NaCl}$ was added, reflecting a salting-out mechanism. This implies that the colloids may exist as peptide 'micelles' whose size is driven by a balance between electrostatic repulsion (attenuated by salt induced 'charge shielding') and weak van der Waals forces between the acyl moieties and aliphatic amino acid side chains. The particles observed $300 \mathrm{sec}$ after the peptide was dissolved in water may correspond to self-assembled systems. As discussed further and 
according to ThT and TEM results, these aggregates are not yet fibrils which are formed with at least 4 hours lag time after dissolution.
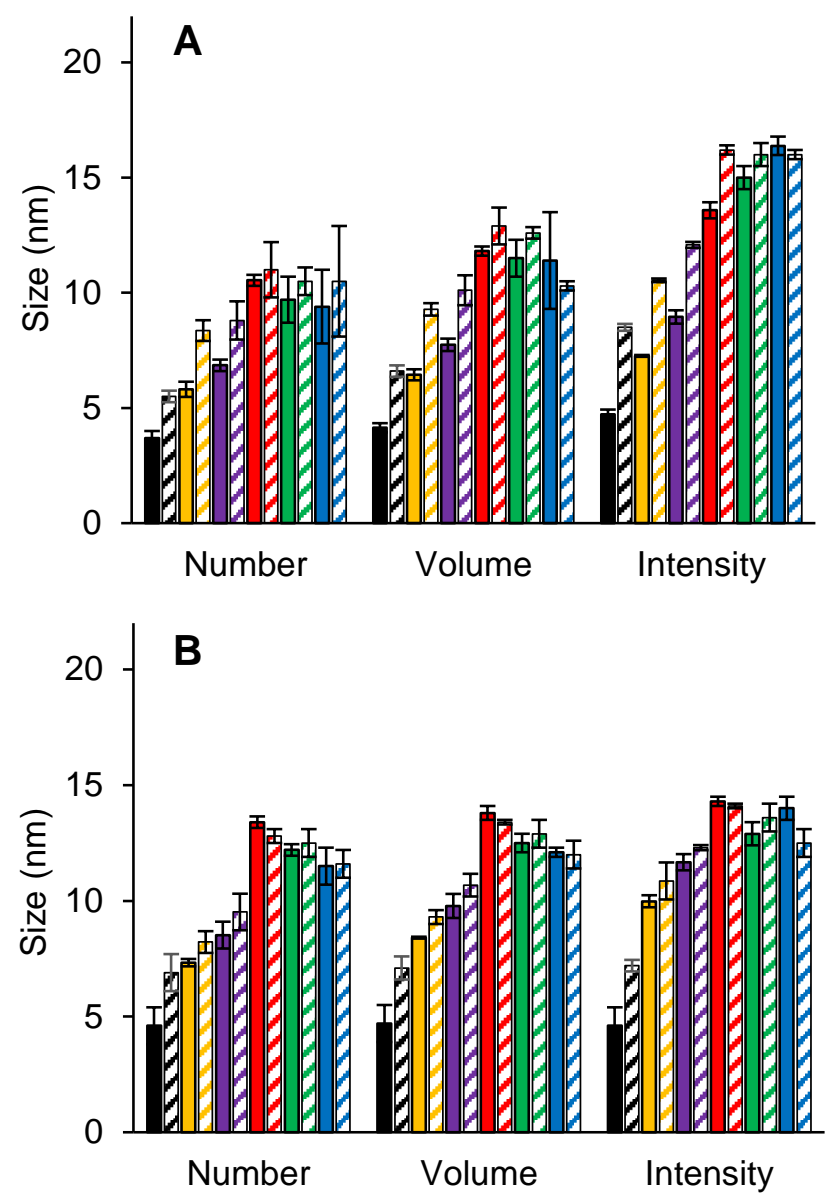

Figure 1. Hydrodynamic diameters ('size') of PEG-cholane:VIP-palm complexes at 0.5:1

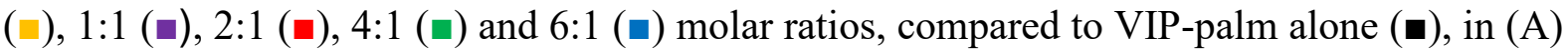
$5 \mathrm{mM}$ acetate (solid fill) and $5 \mathrm{mM}$ acetate, $140 \mathrm{mM} \mathrm{NaCl}$ (striped fill), and (B) $5 \mathrm{mM}$ succinate (solid fill) and $5 \mathrm{mM}$ succinate, $140 \mathrm{mM} \mathrm{NaCl}$ (striped fill), at $\mathrm{pH} \mathrm{5.0,25}{ }^{\circ} \mathrm{C}$, after $300 \mathrm{~s}$ incubation. VIP-palm concentration in all samples: $2 \mathrm{mg} / \mathrm{mL}$.

Complexation of VIP-palm with PEG-cholane at stoichiometries of 2:1 and above generated a particle consistently above $10 \mathrm{~nm}$ diameter (Figure 1). The statistically significant change in particle size between free and complexed peptide implies that VIP-palm was completely associated with PEG-cholane, which was further proved by A4F analysis. 
Particles with a size below $10 \mathrm{~nm}$ were not detected, which may account for the association of VIP-palm with PEG-cholane. However, it should be pointed out that lower sensitivity of DLS occurs for small particles when large size populations are present in the sample, which may result in the underestimation of the former. However, A4F analysis showed that a negligible amount of free peptide was detected (peak at 9 minutes in Figure 2A and B), which accounts for a shift of equilibrium toward peptide association with PEG-cholane under the experimental conditions, namely polymer:peptide ratios. In acetate buffer, in the range of 0:12:1 polymer:peptide molar ratio, an increase of size was observed increasing the PEGcholane:VIP-palm molar ratios and for the addition of NaCl. Above 2:1 PEG-cholane:VIPpalm molar ratio no statistically significant effect on particle size was observed either increasing the polymer:protein molar ratio or the salt addition. In the case of succinate or phosphate buffers (Figure S1) the size increase due to the increase of polymer:protein molar ratio and salt addition were strongly attenuated and no or negligible statistically significant differences were observed in the rank series. The statistically insignificant differences in size observed by DLS for increasing PEG-cholane:VIP-palm ratios above 2:1 polymer:peptide molar ratios in acetate buffer with/without $140 \mathrm{mM} \mathrm{NaCl}$ (Figure 1A) are consistent with the overlap in elution times for the same systems observed by AF4-MALS (Figure 2D). Results for PEG-cholane alone showed a particle size of $16.0 \pm 0.5 \mathrm{~nm}$, corresponding to the micellar structure of this amphiphilic polymer. The small differences between the particle size for PEG-cholane and the PEG-cholane:VIP-palm complexes can be hypothesized as being due to the extent of hydration of the free PEG chains and their association with the peptide surface. Further insight into the specific nature of the structure at molecular level of the PEGcholane:VIP-palm complex is, however, difficult to ascertain through experimental tools alone; we have used computational molecular modelling to obtain insight into this that complements our experimental results and these results are discussed later. 
Asymmetrical Flow Field Flow Fractionation with Multi-Angle Light Scattering (AF4MALS) analyses of the PEG-cholane:VIP-palm complexes was performed to assess their average molecular weight ('mass') and so provide insight to the composition of the supramolecular assembly. ${ }^{57,}{ }^{58}$ In contrast to high performance size exclusion chromatography, AF4 is performed under low shear conditions, minimizing possible supramolecular disassembly and so facilitating determination of the equilibrium state in bulk solution. ${ }^{57,} 59$ Samples were analysed by AF4-MALS under the same solution conditions as for analysis by DLS, with the exception that succinate buffer was omitted since it is not compatible with the AF4 system.

Figure 2A shows that, in the absence of $\mathrm{NaCl}$, free VIP-palm was eluted earlier than the PEG-cholane:VIP-palm complexes. This confirms that VIP-palm was completely associated with PEG-cholane, in agreement with the DLS data. The elution time of the PEGcholane:VIP-palm complex increased with its molar ratio, indicating a likewise increase in the mass of the supramolecular assemblies. Similar results were obtained in the presence of $\mathrm{NaCl}$ (Figure 2B). Here, elution times of free and complexed VIP-palm were consistently later with respect to samples in the absence of $\mathrm{NaCl}$, albeit that elution times tended to merge approaching a PEG-cholane:VIP-palm stoichiometry of 6:1 (Figure 2D). Therefore, the differences in elution times are consistent with the significant difference in particle size recorded by DLS for the free peptide and, to a lesser extent, the polymer:peptide complexes in the presence and absence of $\mathrm{NaCl}$ (Figure 1A). Together, these data imply that high ionic strength buffer causes a change in the molecular mass and hydrodynamic diameter of the aggregated peptide and polymer:peptide assemblies, described further below.

The distribution of the measured masses of the assemblies under each elution peak were deduced as described in the Methods; this permits determination of the homogeneity of the supramolecular mass in each sample (insets, Figure 2A and B). Accordingly, heterogeneous 
assemblies were found for PEG-cholane:VIP-palm molar ratios $<2: 1$. Under these conditions, PEG-cholane cannot saturate the solvent exposed hydrophobic moieties of the peptide (aliphatic amino acid side chains and the palmitoyl) which are therefore free to variously self-assemble with broad stoichiometry, yielding heterogeneous supramolecular aggregates. In contrast, homogeneous mass populations were obtained for samples containing a PEG-cholane:VIP-palm molar ratio of $\geq 2: 1$; the mass being equivalent to 9 to 11 individual complexes (2 PEG-cholane molecules and 1 VIP-palm molecule) in the absence and presence of $\mathrm{NaCl}$, respectively (Table 1). The change in nature of the PEG-cholane:VIP-palm complexes at a 2:1 stoichiometry observed by AF4 is consistent with previously reported calorimetric binding isotherms of PEG-cholane to VIP-palm ${ }^{27}$.

Above 2:1 molar ratio of PEG-cholane:VIP-palm in the presence or absence of $\mathrm{NaCl}$, an increase in mass is observed and the elution time tends to a plateau corresponding to a maximum supramolecular mass of about $300 \mathrm{kDa}$. These trends are in reasonable agreement with the trends observed for complex size in the DLS data, which albeit show a greater distinction for the presence/absence of $\mathrm{NaCl}$ in acetate buffer (Figure 1A). Peptide alone and in low polymer:peptide molar ratio (PEG-cholane:VIP-palm 0.5:1) is observed by AF4MALS to generate colloidal particles with the smallest hydrodynamic diameter (lowest elution times) while simultaneously having a higher molar mass (Figure $2 \mathrm{~A} / \mathrm{B}$ ); this reflects a higher density of the colloidal particles formed at very low PEG-cholane:VIP-palm molar ratio compared to particles formed at high polymer:peptide molar ratios. An interpretation of the trends in mass observed by AF4 should first consider the inherent propensity of VIP-palm to self-assemble, which likely continues to drive the relatively rapid increase in mass of heterogeneous supramolecular assemblies until the PEG-cholane molar excess reaches 2-fold that of the peptide. An excess of PEG-cholane beyond 2 molar equivalents of VIP-palm is associated with a small increase in mass to plateau; this steady state is associated with 
homogenous supramolecular assemblies equivalent in mass to $10 \pm 1$ PEG-cholane:VIP-palm (2:1) complexes dependent on ionic strength. This small increase in mass suggests that, rather than a further increase in the number of PEG-cholane:VIP-palm complexes associated with each assembly, an excess of free PEG-cholane associates with the assemblies. Thus, while the AF4-MALS data proposes a model of each supramolecular assembly wherein a reasonably defined number of PEG-cholane:VIP-palm (2:1) complexes exist, we sought further information by in silico modelling to support this interpretation.
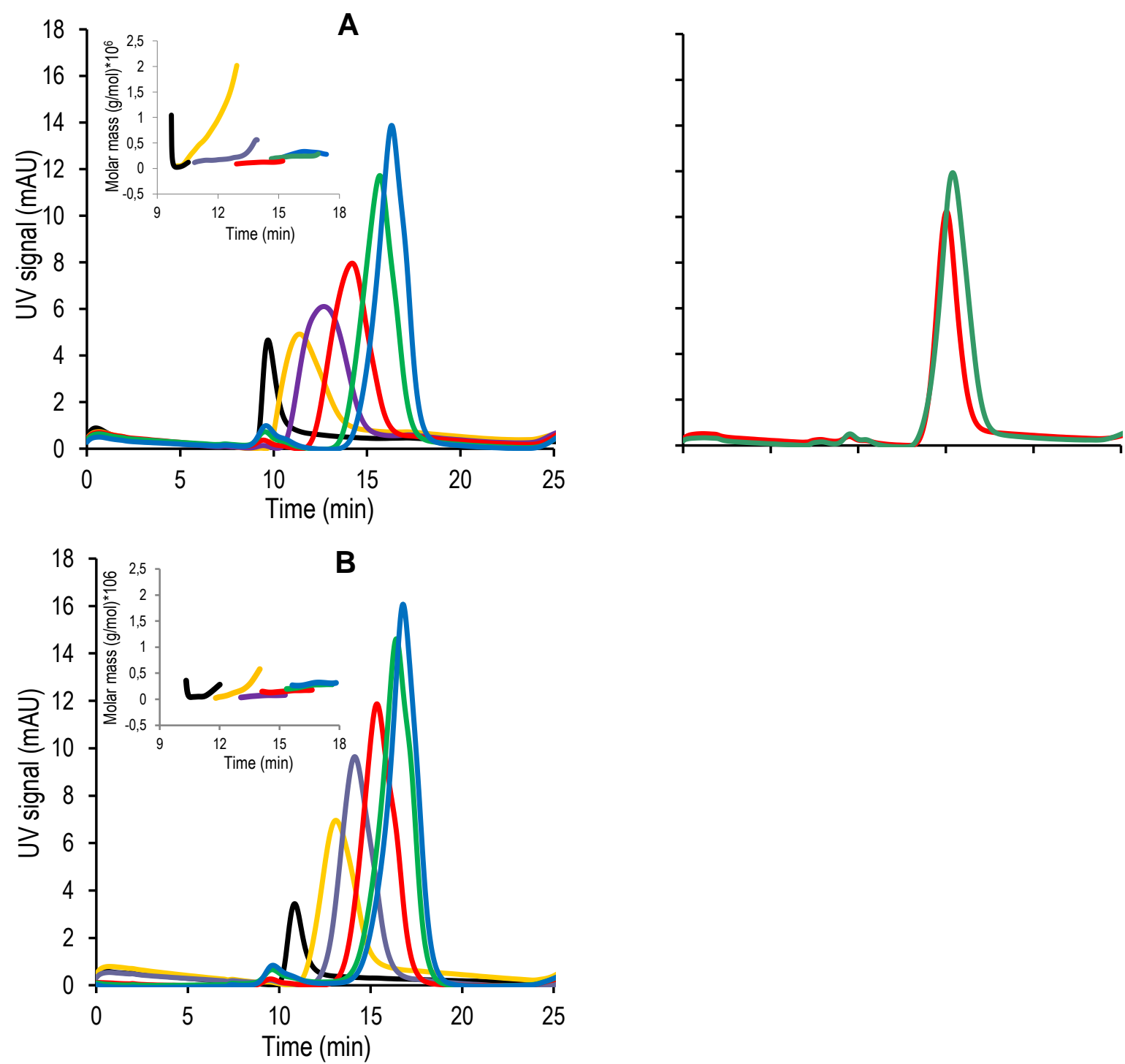

Figure 2. AF4-MALS chromatograms for VIP-palm (-) and PEG-cholane:VIP-palm at molar ratios of $0.5: 1(=), 1: 1(=), 2: 1(=), 4: 1(=)$ and $6: 1(=)$, at $25{ }^{\circ} \mathrm{C}$ in $5 \mathrm{mM}$ acetate buffer, pH 5.0 (A), $5 \mathrm{mM}$ acetate, $140 \mathrm{mM} \mathrm{NaCl}$ buffer, $\mathrm{pH} 5.0$ (B), and $5 \mathrm{mM}$ phosphate, 






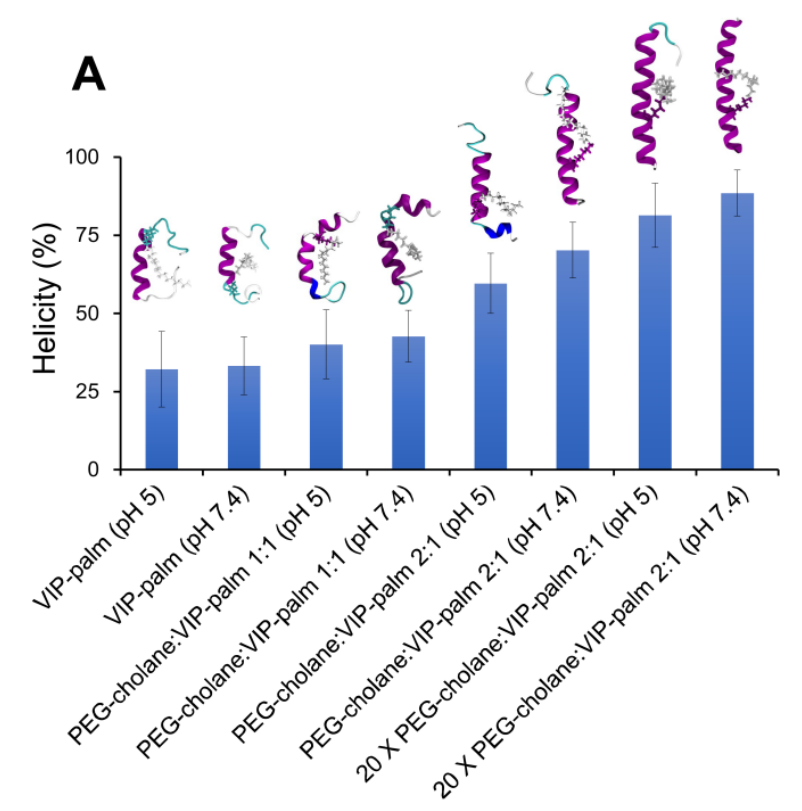

Figure 4. In silico modeling: (A) percent $\alpha$-helix calculated by DSSP analysis and (B) solvent accessible surface area (SASA), for VIP-palm with and without PEG-cholane. Hydrophobic and hydrophilic in the plot refers to the accessible surface area by the hydrophilic and hydrophobic amino acids.

The results above can be visualized using a snapshot from the molecular dynamics simulations, observing that masking of the surface of VIP-palm increases with the number of PEG-cholane molecules and subsequent supramolecular assembly. Figure 5 shows how the PEG-cholane masks the VIP-palm surface around both hydrophobic and hydrophilic amino acids ( $c f$. Figure 4B). The preference for PEG-cholane to be at the peptide/water interface is consistent with the interfacial behavior of PEG and its solubility in either aqueous and nonaqueous solvents. The supramolecular assemblies remained intact during the simulations and support the AF4-MALS data which showed that the assemblies were homogenous at $<2$ mol. equiv. of PEG-cholane. According to the simulation trajectory, as shown in Figure S6, the assembly occurs faster at $\mathrm{pH} 5.0$ than $\mathrm{pH}$ 7.4. 
A

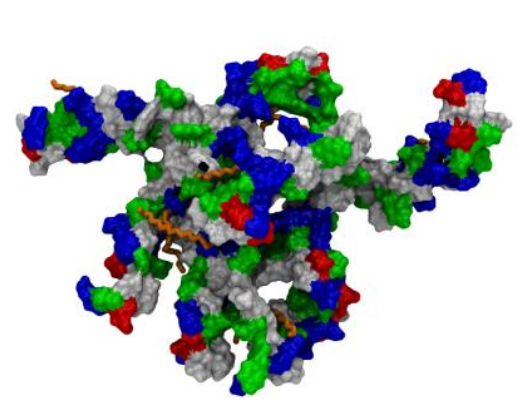

B

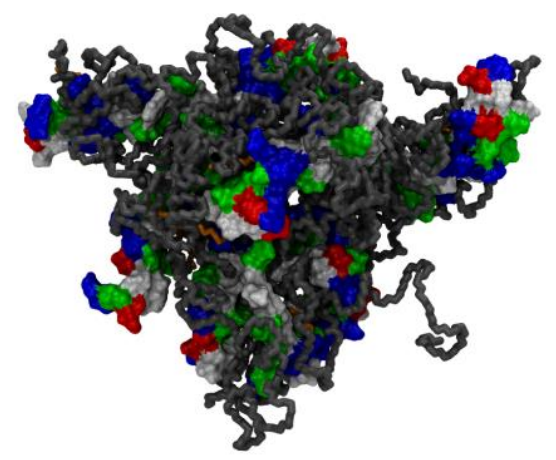

Figure 5. Visualization of a supramolecular assembly composed of 8 PEG-cholane:VIP-palm complexes with 2:1 stoichiometry, shown without (A) and with (B) PEG-cholane molecules. Orange and black stick models represent the palmitoyl chain of VIP-palm and PEG-cholane, respectively. Amino acids are rendered in space-filling model as per the following coloring scheme: hydrophobic residues (white), basic residues (blue), acidic residues (red) and polar residues (green). Palmitate is shown in orange and PEG-cholane molecule is shown in grey.

\section{Excess PEG-cholane alters the VIP-palm aggregation pathway, suppressing fibrillation}

In order to elucidate the mechanism of gelation of VIP-palm, previously reported ${ }^{27}$, aggregation and fibrillation of the peptide in the absence and presence of PEG-cholane, was studied by spectrofluorometric assay using Thioflavin T (ThT), which intercalates within $\beta$ sheet structures of amyloid-likefibrils. ${ }^{54,62}$

Figure 6 shows that VIP-palm alone at relatively low concentration $(2 \mathrm{mg} / \mathrm{ml})$ fibrillated in high ionic strength solution irrespective of the buffer species. This is consistent with the observed salting-out effect which promoted VIP-palm self-association ( $c f$. Figure 1), generating nuclei which could accelerate fibrillation. Other studies have shown that high salt concentrations screen out the net charge of peptide molecules, reducing long range electrostatic repulsion and thus favouring short range van der Waals interactions. ${ }^{6,}$ 63, 64 This 
hypothesis may also be applied to the VIP-palm, which harbours a strong net positive charged at pH 5.0 (pI, 10.04). In acetate buffer, VIP-palm fibrillation is minimal and the lag phase extended in comparison to succinate buffer (Figure 6A). This is probably due to the higher ionic strength of the succinate buffer and its divalent nature which therefore screens out the net positive charge of the peptide more effectively. Lower VIP-palm concentrations were studied in succinate buffer and did not perturb the lag time or elongation phase but did reduce the plateau and thereby the number of fibrils at steady state (Figure $6 \mathrm{C}, \mathrm{D}$ ), in agreement with previous reports. ${ }^{55}$
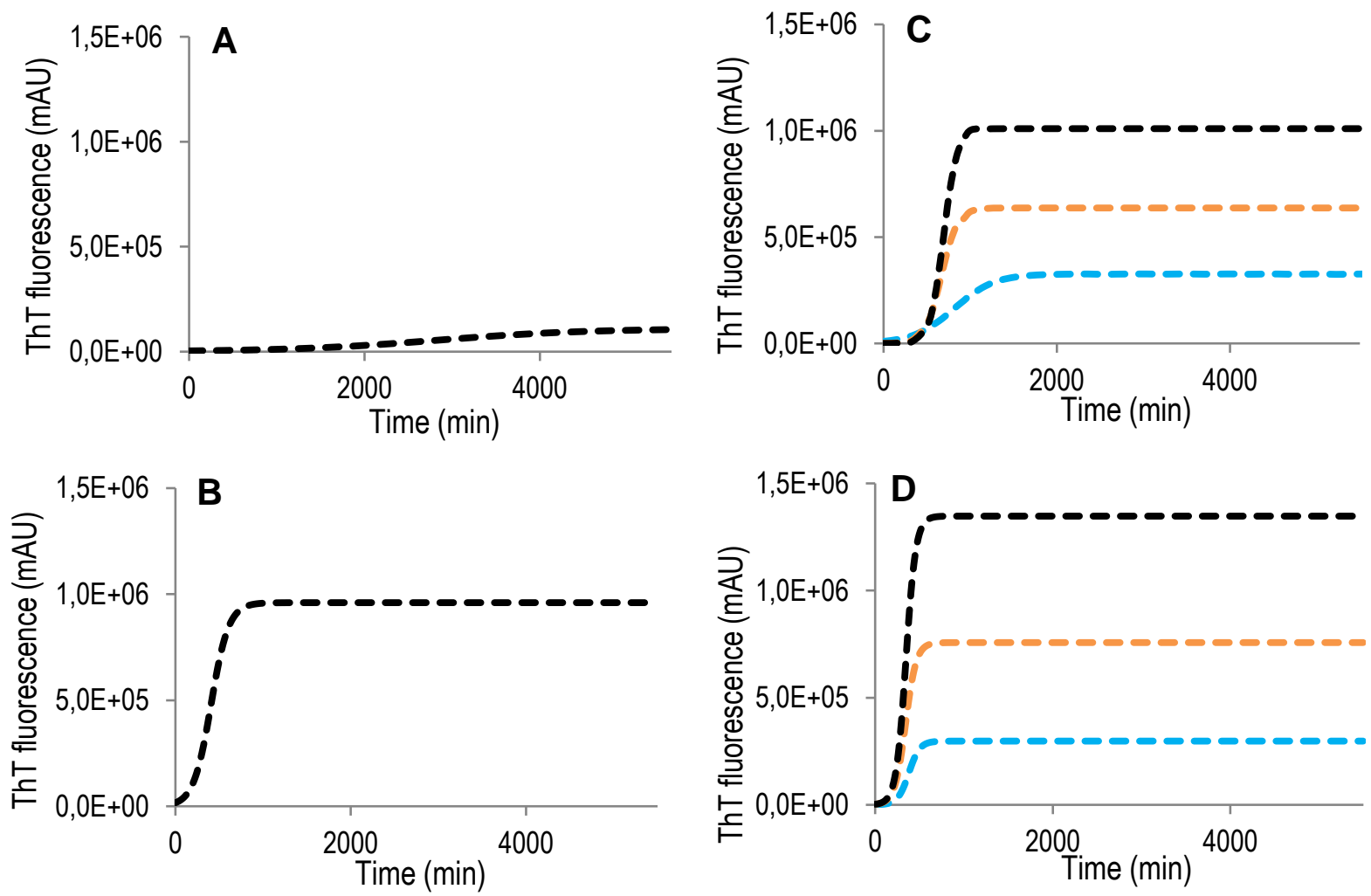

Figure 6. ThT assay fibrillation profiles of VIP-palm at $37^{\circ} \mathrm{C}, \mathrm{pH} 5$, in $5 \mathrm{mM}$ acetate (A); 5 $\mathrm{mM}$ acetate, $140 \mathrm{mM} \mathrm{NaCl}$ (B); $5 \mathrm{mM}$ succinate (C); $5 \mathrm{mM}$ succinate, $140 \mathrm{mM} \mathrm{NaCl}$ (D). Peptide concentration: $0.5 \mathrm{mg} / \mathrm{mL}(=), 1 \mathrm{mg} / \mathrm{mL}(=)$ and $2 \mathrm{mg} / \mathrm{mL}(=)$. 
Figure 7 shows the effect of temperature, buffer species, ionic strength and complexation with PEG-cholane on the fibrillation of VIP-palm. Temperature had no discernible effect on the lag phase but played a dominant role in the elongation phase, markedly accelerating the formation of fibrils independently of buffer species and ionic strength. Previous work provides evidence that increased peptide conformational flexibility and structural conversion to partially unfolded states together promote fibrillation. ${ }^{63}$ This is in agreement with the particularly rapid fibrillation of VIP-palm alone at $50{ }^{\circ} \mathrm{C}$, the temperature at which the peptide conformation loses helical structure ( $c f$. Figure S2), i.e. the key step in the fibrillation of the peptide would appear to be the structural transition from a helical to random structure. A similar mechanism helps explain the attenuation of fibrillation by PEG-cholane, i.e. irrespective of temperature, buffer species and ionic strength, for an increase in PEGcholane:VIP-palm stoichiometry the rate of fibrillation during the elongation phase is reduced and the lag phase is extended (Figure 6 and Table S1). Since a greater excess of PEG-cholane generated supramolecular assemblies whose environments acted to increasingly stabilize the helical structure of VIP-palm ( $c f$. Figure S2), it follows that transition to a conformation associated with nucleation and elongation was highly restricted.
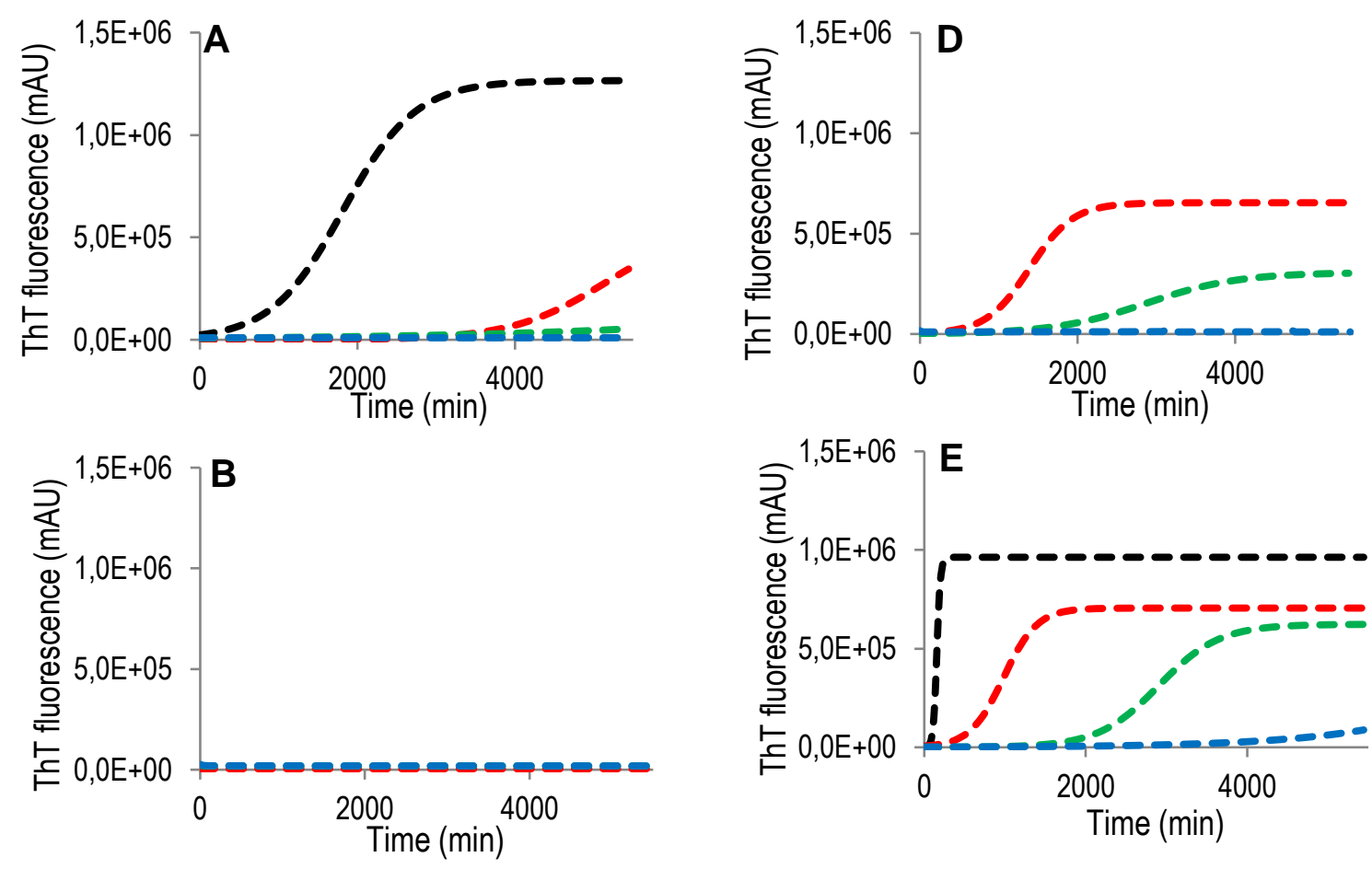

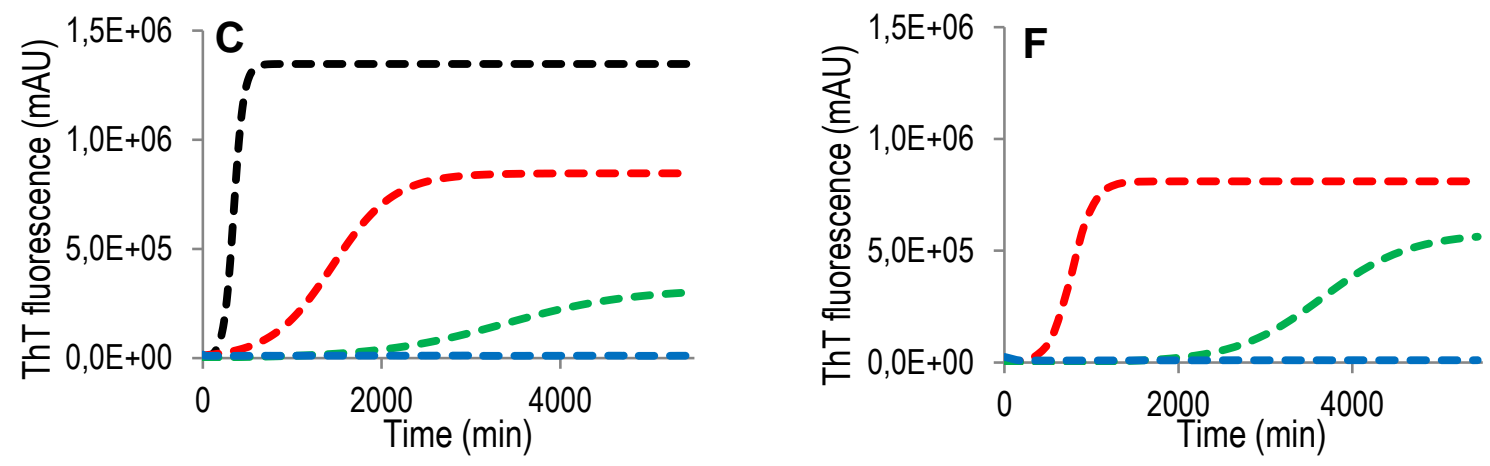

Figure 7. ThT assay fibrillation profiles for PEG-cholane:VIP-palm at molar ratios of 2:1 $(=), 4: 1(=)$ and $6: 1(=)$, and of VIP-palm alone $(=)$, in $5 \mathrm{mM}$ succinate, $140 \mathrm{mM} \mathrm{NaCl}, \mathrm{pH}$ 5.0 (A, C, E); $5 \mathrm{mM}$ phosphate, $140 \mathrm{mM} \mathrm{NaCl}, \mathrm{pH} 7.4(\mathrm{~B}, \mathrm{D}, \mathrm{F})$, at $25^{\circ} \mathrm{C}(\mathrm{A}, \mathrm{B}), 37{ }^{\circ} \mathrm{C}(\mathrm{C}$, D) and $50{ }^{\circ} \mathrm{C}(\mathrm{E}, \mathrm{F})$. VIP-palm concentration in all samples: $2 \mathrm{mg} / \mathrm{mL}$.

The addition of $\mathrm{NaCl}$ to the PEG-cholane:VIP-palm complexes in solution had the effect to promote fibrillation, which was most notable in acetate buffer (Figure S7). This reflects the ThT data for VIP-palm alone, and may in part be attributed to surface charge screening and a reduction in electrostatic repulsion between peptide molecules. $\mathrm{NaCl}$ may also act to stabilize the VIP-palm helical conformation, though given the CD data, this would be minimal and secondary to the effect of complexation with PEG-cholane. Since the addition of $\mathrm{NaCl}$ to acetate buffer generated PEG-cholane:VIP-palm supramolecular assemblies with a higher molecular weight ( $c f$. Figure 2D), a change in the immediate peptide environment may be inferred. However, simulations showed no significant change in exposure of VIP-palm to solvent or PEG/palmitoyl moieties, or hydrogen bonding in excess PEG-cholane ( $c f$. Figures $\mathrm{S} 4, \mathrm{~S} 5)$. The combined change in buffer species and $\mathrm{pH}$ had little effect on VIP-palm fibrillation in the presence of excess PEG-cholane, albeit that peptide fibrillation was completely suppressed at PEG-cholane:VIP-palm molar ratios above 4:1 in phosphate buffer, 
$\mathrm{pH} 7.4$, over the assay period (Figure 7). To investigate this effect further, the assay was performed at higher $\mathrm{pH}(7.4 v s$ 5) for the same buffer species (succinate, Table S1). At PEGcholane:VIP-palm molar ratios of 2:1 and 4:1, lag times were somewhat longer at near neutral $\mathrm{pH}$. While this $\mathrm{pH}$ shift decreases the net VIP-palm charge (above), it is also associated with a higher affinity of PEG-cholane for VIP-palm ${ }^{27}$ which in turn may sterically hinder nucleation and elongation. The effect of $\mathrm{pH}$ does not negate the effect of buffer species on fibrillation, particularly the difference observed between succinate and acetate buffers, pH 5.0 (Figure S7). Since the ThT assay does not inform on fibril morphology at plateau, the effect of buffer species (and polymer) on VIP-palm fibrillation was investigated further by transmission electron microscopy. 

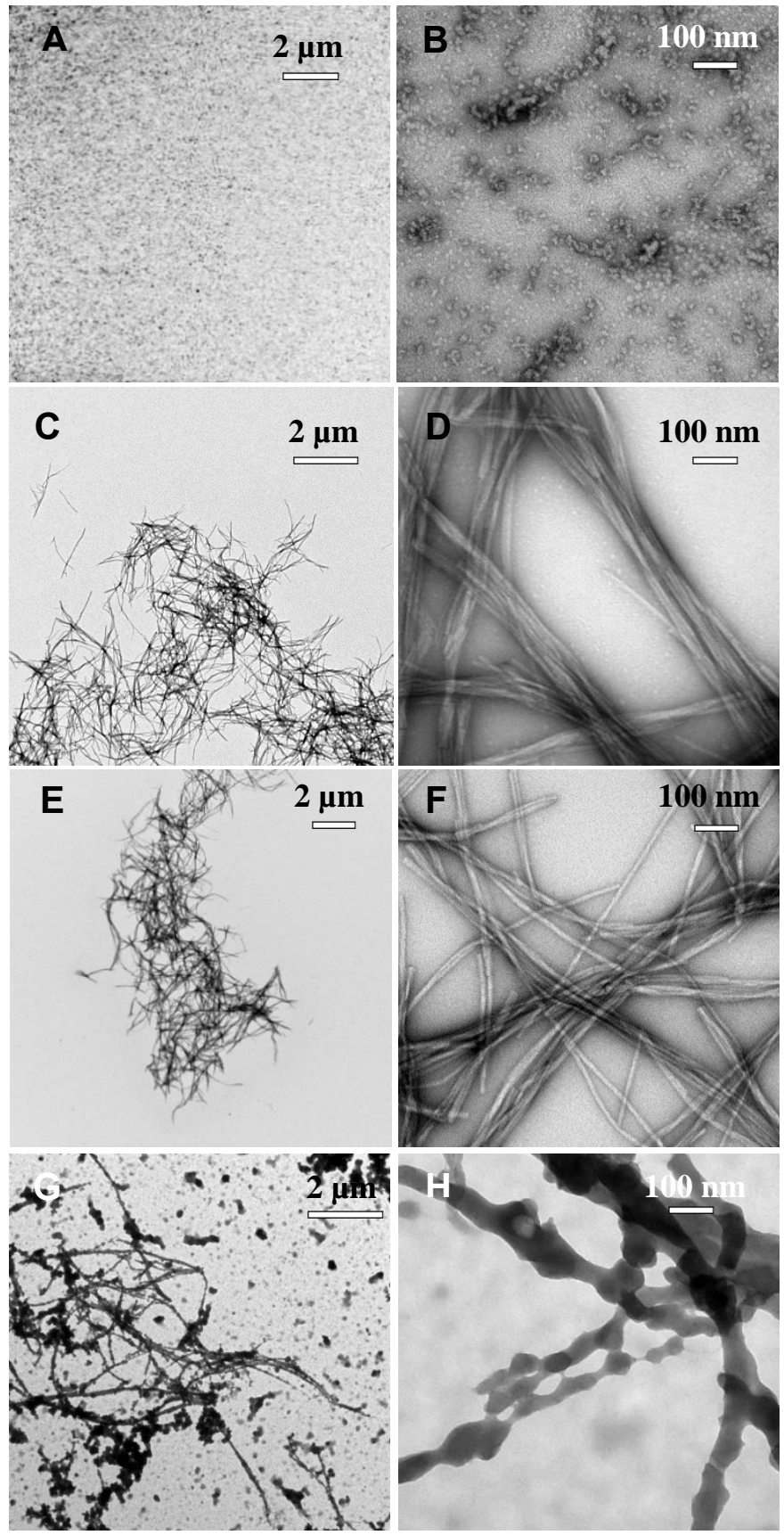

Figure 8. TEM images of $2 \mathrm{mg} / \mathrm{mL}$ VIP-palm incubated at $37{ }^{\circ} \mathrm{C}$, pH 5.0 in $5 \mathrm{mM}$ acetate (A, B); pH 5.0 in $5 \mathrm{mM}$ acetate, $140 \mathrm{mM} \mathrm{NaCl}(\mathrm{C}, \mathrm{D}) ; \mathrm{pH} 5.0$ in $5 \mathrm{mM}$ succinate (E, F); $\mathrm{pH}$ 5.0 in $5 \mathrm{mM}$ succinate, $140 \mathrm{mM} \mathrm{NaCl}(\mathrm{G}, \mathrm{H})$.

The micrographs are in agreement with the ThT assay data of VIP-palm in acetate/succinate buffer without $\mathrm{NaCl}$ (Figure 7, $c f$. Figure S7), that is, fibrils were not 
observed in acetate buffer but were observed in succinate buffer. In acetate buffer, only amorphous aggregates around $20 \mathrm{~nm}$ diameter were present and were incapable of nucleating elongation into fibrils (at least over these time scales, Figure 8 A, B), and may have been unstable, existing in equilibrium with VIP-palm in solution. Although the amorphous aggregates appeared to be of a size similar to the hydrodynamic diameter measured by DLS (cf. Figure 1), it is not the case that the same species are being observed given the very different condition of sample incubation for the purpose of each of the tests (DLS analysis was performed without delay to assess colloidal size of assemblies, whereas ThT and TEM samples underwent agitation and incubation over several days to investigate the kinetic of fibrillation). Since the ThT assay for VIP-palm in acetate buffer (no $\mathrm{NaCl}$ ) showed only very weak evidence of fibrillation, these amorphous aggregates presumably stain very poorly with ThT because of their inherent structural disorder. Figure $8 \mathrm{C}, \mathrm{D}$ shows that the addition of $\mathrm{NaCl}$ to acetate buffer induced the formation of quite heterogeneous fibrils with a length of $2.65 \pm 1.45 \mu \mathrm{m}$ and thickness of $12.6 \pm 4.6 \mathrm{~nm}$; a marked change which is reflected in the ThT assay. These fibrils are similar to those formed in succinate buffer (without $\mathrm{NaCl}$, Figure $8 \mathrm{E}$, F), which are heterogeneous with a length of $1.25 \pm 0.55 \mu \mathrm{m}$ and a thickness of $11.9 \pm 6.3$ $\mathrm{nm}$. This effect of succinate buffer may be due to its divalent charge which has been shown to promote the peptide intermolecular association via charge-to-charge crosslinking. ${ }^{6}$

The addition of $\mathrm{NaCl}$ to succinate buffer caused a distinct shift from simple elongated fibrils to branched and/or nodulated fibrils $3.5 \pm 0.6 \mu \mathrm{m}$ in length and $64.1 \pm 18.1$ in thickness (Figure $8 \mathrm{G}, \mathrm{H}$ ), and which were also denser (darker staining with contrast agent). This behaviour seems to indicate that in succinate buffer fibrillation takes place according to a multi-step process: 1) nucleation and elongation of primary fibrils, 2) nucleation of nodules on these primary fibril, 3) secondary fibrillation generating branched fibrils. 


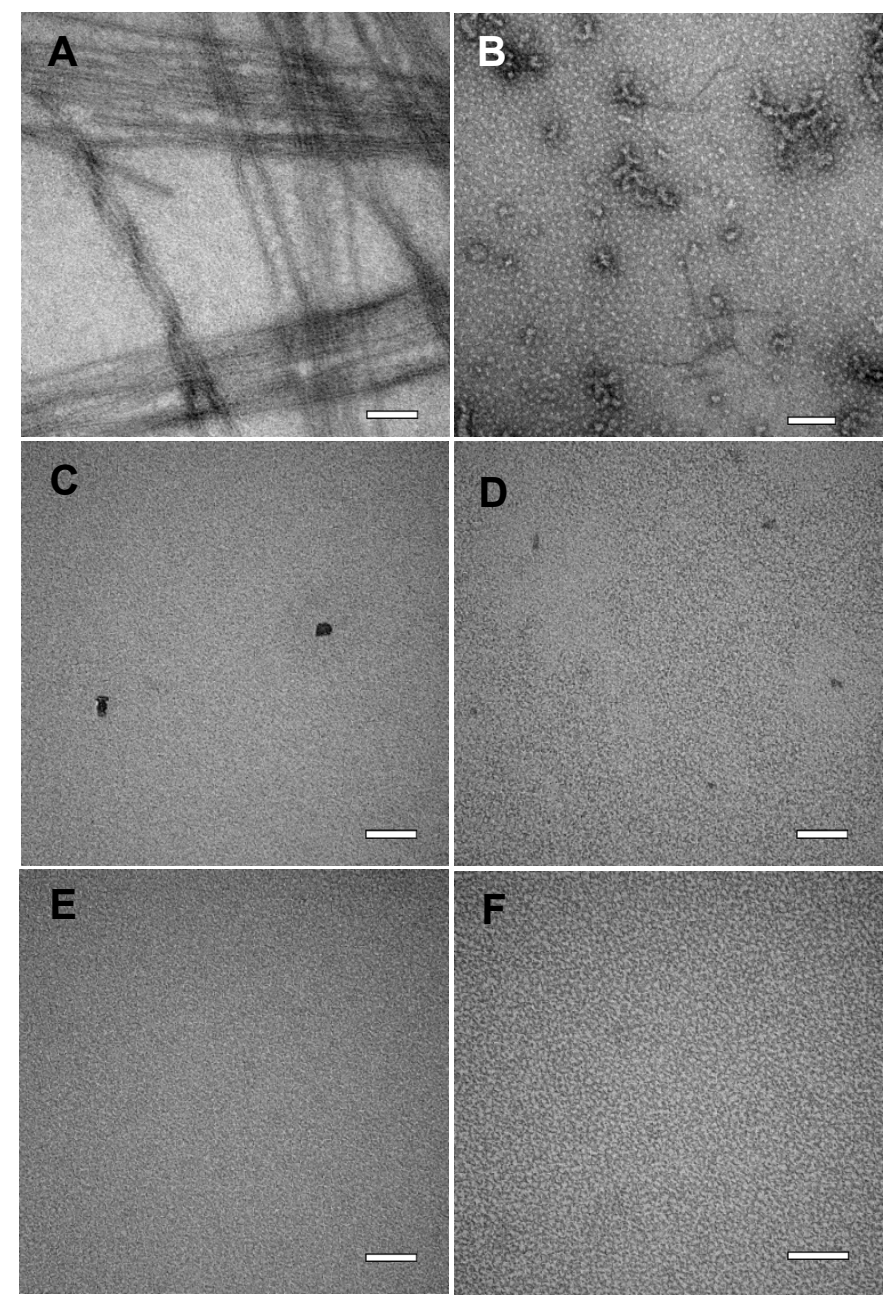

Figure 9. TEM images of PEG-cholane:VIP-palm at 2:1 (A, B), 4:1 (C, D) and 6:1 (E, F) molar ratios, incubated at $37^{\circ} \mathrm{C}, \mathrm{pH} 5.0$, in $5 \mathrm{mM}$ acetate, $140 \mathrm{mM} \mathrm{NaCl}(\mathrm{A}, \mathrm{C}, \mathrm{E}), 5 \mathrm{mM}$ succinate, $140 \mathrm{mM} \mathrm{NaCl}(\mathrm{B}, \mathrm{D}, \mathrm{F})$. Scale bar $=100 \mathrm{~nm}$. Figures S8-10 show micrographs of the samples at lower resolutions. VIP-palm concentration in all samples: $2 \mathrm{mg} / \mathrm{mL}$.

VIP-palm was incubated with increasing molar ratios of PEG-cholane and samples were imaged by TEM, equivalent to the ThT assays performed at $37{ }^{\circ} \mathrm{C}$ in acetate and succinate buffers at high ionic strength. The micrographs in Figure 8 are broadly in agreement with the ThT assay data but with notably differences. A PEG-cholane:VIP-palm molar ratio of 2:1 was not sufficient to prevent the formation of fibrils, which were clearly seen in acetate 
buffer $(3.7 \pm 0.7 \mu \mathrm{m}$ length and $14.8 \pm 5.4 \mathrm{~nm}$ thickness $)$ but sparsely in succinate buffer, appearing truncated and branched (111.7 $\pm 9.8 \mathrm{~nm}$ length and $11.7 \pm 1.7 \mathrm{~nm}$ thickness) amongst large, globular aggregates that may represent nuclei (Figure 9 A, B). The distinct morphologies of the fibrils seen for VIP-palm alone in acetate and succinate buffers with $\mathrm{NaCl}$ persisted in the presence of PEG-cholane. Although the ThT assay showed that some level of aggregation remained at a PEG-cholane:VIP-palm molar ratio of 4:1, no fibrils were observed by TEM, although a very few globular aggregates (dark staining) appeared amongst smaller amorphous aggregates (Figure $9 \mathrm{C}, \mathrm{D}$ ). This PEG-cholane excess must therefore be sufficient to prevent elongation of the aggregates into fibrils, at least at the timescales investigated, either by sterically hindering recruitment of additional VIP-palm molecules or by altering the nature of the aggregation pathway as a consequence of stabilizing the peptide helical conformation. The micrographs showed that a PEG-cholane excess of 6 mol. equiv. of VIP-palm resulted in no observable fibrils or globular aggregates (Figure $9 \mathrm{E}, \mathrm{F}$ ), consistent with the equivalent ThT assays which showed no evidence of fibrillation.

\section{CONCLUSIONS}

From the elegant observation that physical PEGylation can be achieved for lipidated peptides as for proteins with a resultant extension of half-life in vivo, ${ }^{27}$ we have now characterised the complex at the supramolecular level. This is necessary because the nature of the peptide:polymer complex is less easily defined than analogous supramolecular assemblies such as those strictly governed by host:guest interactions (e.g. cyclodextrin or cucurbit[n]uril hosts). ${ }^{65}$, 66 While each VIP-palm molecule was previously demonstrated to bind around 2 PEG-cholane molecules, only indirect evidence for their self-assembly could be acquired from the observation of an increasing physical stability of VIP-palm. 
While DLS data in this study showed distinct nanoparticle sizes for the different buffer and PEG-cholane:VIP-palm stoichiometries, more sophisticated analysis was achieved using AF4-MALS. Modelling the elution profile of the assemblies using this low-shear separation technique permitted estimation of their corresponding molecular weight and associated components. For example, from the AF4-MALS data it can be inferred that above a 2:1 PEGcholane:VIP-palm molar ratio, the excess of free PEG-cholane molecules associate with the complexes, contributing to their increase in mass, while the number of complexes participating in the supramolecular assembly remain quite constant. It is reasonable to assume that the supramolecular environment experienced by VIP-palm reflects that of a micellar system and so lends itself well to the stabilization of a helical conformation. This in turn presents a rate limiting step for transition to $\beta$-sheet structure and the suppression of fibrillation, as observed by ThT assay and TEM. In order to support the experimental data, we used in silico modelling.

The simulations were initially tested for 1:1 and 2:1 PEG-cholane:VIP-palm stoichiometries and subsequent assembly of these complexes. The resulting, quantitative data demonstrated that 2 mol. equiv. of PEG-cholane was key to stabilizing the helical conformation and bringing about a step change in the fraction of VIP-palm exposed to the bulk water, i.e. the peptide backbone became more intimately associated with either PEG or palmitoyl moieties. Moreover, assembly of the complexes resulted in a continued decline in the SASA of VIP-palm which could then be related to an increase in helical structure. Greater inhibition of VIP-palm aggregation and fibrillation with increasing excess of PEG-cholane, observed by ThT assay and TEM, is therefore most likely due to: i) steric inhibition by additional PEG chains within the supramolecular assembly and ii) a more dominant and stable helical conformation. 
The observation that at least 4 mol. equiv. of PEG-cholane resulted in a VIP-palm solution which was particularly physically stable under different buffers and ionic strengths (including isotonic) is relevant to the formulation of peptides. This work suggests that PEG-cholane may be a useful excipient when designing formulation approaches for potential, therapeutic lipidated peptides which are known to spontaneously undergo self-association, aggregation and fibrillation.

\section{Supporting Information}

Complete details of VIP-palm fibrillation kinetic; size analysis of PEG-cholane:VIP-palm assembly in $20 \mathrm{mM}$ phosphate, $140 \mathrm{mM} \mathrm{NaCl}, \mathrm{pH}$ 7.4; VIP-palm secondary structure calculated from CD spectra; in silico simulations of VIP-palm surface accessible area, of intra-molecular (between VIP-palm) and inter-molecular (PEG-cholane:VIP-palm) hydrogen bonds, of radius of gyration for the PEG-cholane:VIP-palm; ThT assay fibrillation profiles under different osmotic conditions and buffer ions; TEM images at lower magnification.

\section{ACKNOWLEDGMENT}

EA was supported by funding from MedImmune, Ltd. We are thankful to Dr Kevin Jackson (Wyatt Technology Corporation) for technical support on the AF4-MALS analysis. 


\section{REFERENCES}

1. Usmani, S. S.; Bedi, G.; Samuel, J. S.; Singh, S.; Kalra, S.; Kumar, P.; Ahuja, A. A.; Sharma, M.; Gautam, A.; Raghava, G. P., THPdb: Database of FDA-approved peptide and protein therapeutics. PloS one 2017, 12, (7), e0181748.

2. Fosgerau, K.; Hoffmann, T., Peptide therapeutics: current status and future directions. Drug discovery today 2015, 20, (1), 122-128.

3. Sharfstein, S. T., Non-protein biologic therapeutics. Curr. Opin. Biotechnol. 2018, 53, $65-75$.

4. Akash, M. S. H.; Rehman, K.; Tariq, M.; Chen, S., Development of therapeutic proteins: advances and challenges. Turk. J. Biol. 2015, 39, (3), 343-358.

5. Balu-Iyer, S. V.; Miclea, R. D.; Purohit, V. S., Formulation and Delivery Issues of Therapeutic Proteins. Handbook of Pharmaceutical Biotechnology, S. C. Gad (Ed.) 2006, 737-755.

6. Chi, E. Y.; Krishnan, S.; Randolph, T. W.; Carpenter, J. F., Physical stability of proteins in aqueous solution: mechanism and driving forces in nonnative protein aggregation. Pharm. Res. 2003, 20, (9), 1325-1336.

7. Wang, W.; Warne, N. W., Approaches to Managing Protein Aggregation in Product Development. John Wiley \& Sons, Inc. : 2010; p 333-365.

8. Weinberg, W. C.; Ha, L.; Kirshner, S. L.; Verthelyi, D. I., Regulatory perspective on aggregates as a product quality attribute. In Aggregation of Therapeutic Proteins, Roberts, W. W. J., Ed. John Wiley \& Sons, Inc. : 2010; pp 435-451.

9. Ivanova, M. I.; Sievers, S. A.; Sawaya, M. R.; Wall, J. S.; Eisenberg, D., Molecular basis for insulin fibril assembly. Proc. Natl. Acad. Sci. U. S. A. 2009, 106, (45), 1899018995.

10. Pedersen, J. S.; Dikov, D.; Flink, J. L.; Hjuler, H. A.; Christiansen, G.; Otzen, D. E., The changing face of glucagon fibrillation: structural polymorphism and conformational imprinting. J. Mol. Biol. 2006, 355, (3), 501-523.

11. Ryan, T. M.; Roberts, B. R.; Streltsov, V. A.; Nuttall, S. D.; Masters, C. L., The Role of A $\beta$ in Alzheimer's Disease. Wiley-VCH Verlag GmbH \& Co. KGaA: 2013; p 263-293.

12. Knowles, T. P.; Vendruscolo, M.; Dobson, C. M., The amyloid state and its association with protein misfolding diseases. Nat. Rev. Mol. Cell Biol. 2014, 15, (6), 384-396. 13. Broom, A.; Jacobi, Z.; Trainor, K.; Meiering, E. M., Computational tools help improve protein stability but with a solubility tradeoff. J. Biol. Chem. 2017, 292, (35), 1434914361.

14. Pasut, G.; Veronese, F. M., State of the art in PEGylation: the great versatility achieved after forty years of research. J. Controlled Release 2012, 161, (2), 461-472.

15. Bruno, B. J.; Miller, G. D.; Lim, C. S., Basics and recent advances in peptide and protein drug delivery. Ther. Deliv. 2013, 4, (11), 1443-1467.

16. Gauthier, M. A.; Klok, H.-A., Polymer-protein conjugates: an enzymatic activity perspective. Polym. Chem. 2010, 1, (9), 1352-1373.

17. Choudhary, S.; Kishore, N.; Hosur, R. V., Inhibition of insulin fibrillation by osmolytes: Mechanistic Insights. Sci. Rep. 2015, 5.

18. Wang, W., Advanced protein formulations. Protein Sci. 2015, 24, (7), 1031-1039.

19. Kurinomaru, T.; Shiraki, K., Noncovalent PEGylation of 1-Asparaginase Using PEGylated Polyelectrolyte. J. Pharm. Sci. 2015, 104, (2), 587-592.

20. Luengo-Alonso, C.; Torrado, J. J.; Ballesteros, M. P.; Malfanti, A.; Bersani, S.; Salmaso, S.; Caliceti, P., A novel performing PEG-cholane nanoformulation for Amphotericin B delivery. Int. J. Pharm. 2015, 495, (1), 41-51. 
21. Salmaso, S.; Bersani, S.; Mastrotto, F.; Tonon, G.; Schrepfer, R.; Genovese, S.; Caliceti, P., Self-assembling nanocomposites for protein delivery: Supramolecular interactions between PEG-cholane and rh-G-CSF. J. controlled Release 2012, 162, (1), 176184.

22. Salmaso, S.; Bersani, S.; Scomparin, A.; Balasso, A.; Brazzale, C.; Barattin, M.; Caliceti, P., A novel soluble supramolecular system for sustained rh-GH delivery. $J$. Controlled Release 2014, 194, 168-177.

23. Knudsen, L., Liraglutide: the therapeutic promise from animal models. Int. J. Clin. Pract. 2010, 64, (s167), 4-11.

24. Youngster, S.; Wang, Y. S.; Grace, M.; Bausch, J.; Bordens, R.; Wyss, D. F., Structure, biology, and therapeutic implications of pegylated interferon alpha-2b. Curr. Pharm. Des. 2002, 8, (24), 2139-57.

25. Li, Y.; Wang, Y.; Wei, Q.; Zheng, X.; Tang, L.; Kong, D.; Gong, M., Variant fatty acid-like molecules Conjugation, novel approaches for extending the stability of therapeutic peptides. Sci. Rep. 2015, 5.

26. Hedegaard, S. F.; Cárdenas, M.; Barker, R.; Jorgensen, L.; Van de Weert, M., Lipidation Effect on Surface Adsorption and Associated Fibrillation of the Model Protein Insulin. Langmuir 2016, 32, (28), 7241-7249.

27. Ambrosio, E.; Barattin, M.; Bersani, S.; Shubber, S.; Uddin, S.; van der Walle, C. F.; Caliceti, P.; Salmaso, S., A novel combined strategy for the physical PEGylation of polypeptides. J. Controlled Release 2016, 226, 35-46.

28. Arosio, P.; Knowles, T. P.; Linse, S., On the lag phase in amyloid fibril formation. Phys. Chem. Chem. Phys. 2015, 17, (12), 7606-7618.

29. Weinberg, W. C.; Ha, L.; Kirshner, S. L.; Verthelyi, D. I., Regulatory perspective on aggregates as a product quality attribute. John Wiley \& Sons, Inc. : 2010; p 435-451.

30. Roberts, C. J., Protein aggregation and its impact on product quality. Curr. Opin. Biotechnol. 2014, 30, 211-217.

31. Wu, D.; Lee, D.; Sung, Y. K., Prospect of vasoactive intestinal peptide therapy for COPD/PAH and asthma: a review. Respir. Res. 2011, 12, (1), 45.

32. Gonzalez-Rey, E.; Fernandez-Martin, A.; Chorny, A.; Martin, J.; Pozo, D.; Ganea, D.; Delgado, M., Therapeutic effect of vasoactive intestinal peptide on experimental autoimmune encephalomyelitis: down-regulation of inflammatory and autoimmune responses. Am. J. Pathol. 2006, 168, (4), 1179-1188.

33. M White, C.; Ji, S.; Cai, H.; Maudsley, S.; Martin, B., Therapeutic potential of vasoactive intestinal peptide and its receptors in neurological disorders. CNS Neurol. Disord. Drug Targets 2010, 9, (5), 661-666.

34. Rose, P. W.; Prlić, A.; Bi, C.; Bluhm, W. F.; Christie, C. H.; Dutta, S.; Green, R. K.; Goodsell, D. S.; Westbrook, J. D.; Woo, J., The RCSB Protein Data Bank: views of structural biology for basic and applied research and education. Nucleic Acids Res. 2014, 43, (D1), D345-D356.

35. Umetsu, Y.; Tenno, T.; Goda, N.; Shirakawa, M.; Ikegami, T.; Hiroaki, H., Structural difference of vasoactive intestinal peptide in two distinct membrane-mimicking environments. Biochim. Biophys. Acta, Proteins Proteomics 2011, 1814, (5), 724-730.

36. Pettersen, E. F.; Goddard, T. D.; Huang, C. C.; Couch, G. S.; Greenblatt, D. M.; Meng, E. C.; Ferrin, T. E., UCSF Chimera - A visualization system for exploratory research and analysis. Journal of Computational Chemistry 2004, 25, (13), 1605-1612.

37. Jo, S.; Kim, T.; Iyer, V. G.; Im, W., CHARMM-GUI: A web-based graphical user interface for CHARMM. J. Comput. Chem. 2008, 29, (11), 1859-1865.

38. Pronk, S.; Pall, S.; Schulz, R.; Larsson, P.; Bjelkmar, P.; Apostolov, R.; Shirts, M. R.; Smith, J. C.; Kasson, P. M.; van der Spoel, D.; Hess, B.; Lindahl, E., GROMACS 4.5: a high- 
throughput and highly parallel open source molecular simulation toolkit. Bioinformatics (Oxford, England) 2013, 29, (7), 845-54.

39. Stepniewski, M.; Pasenkiewicz-Gierula, M.; Róg, T.; Danne, R.; Orlowski, A.; Karttunen, M.; Urtti, A.; Yliperttula, M.; Vuorimaa, E.; Bunker, A., Study of PEGylated lipid layers as a model for PEGylated liposome surfaces: molecular dynamics simulation and Langmuir monolayer studies. Langmuir 2011, 27, (12), 7788-7798.

40. Magarkar, A.; Karakas, E.; Stepniewski, M.; Róg, T.; Bunker, A., Molecular dynamics simulation of PEGylated bilayer interacting with salt ions: a model of the liposome surface in the bloodstream. J. Phys. Chem. B 2012, 116, (14), 4212-4219.

41. Magarkar, A.; Dhawan, V.; Kallinteri, P.; Viitala, T.; Elmowafy, M.; Róg, T.; Bunker, A., Cholesterol level affects surface charge of lipid membranes in saline solution. Sci. Rep. 2014, 4.

42. Magarkar, A.; Róg, T.; Bunker, A., Molecular dynamics simulation of PEGylated membranes with cholesterol: building toward the DOXIL formulation. J. Phys. Chem. B 2014, 118, (28), 15541-15549.

43. Parrinello, M.; Rahman, A., Polymorphic transitions in single crystals: A new molecular dynamics method. J. Appl. Phys. 1981, 52, (12), 7182-7190.

44. Nosé, S., A unified formulation of the constant temperature molecular dynamics methods. J. Chem. Phys. 1984, 81, (1), 511-519.

45. Jorgensen, W. L.; Chandrasekhar, J.; Madura, J. D.; Impey, R. W.; Klein, M. L., Comparison of simple potential functions for simulating liquid water. J. Chem. Phys. 1983, 79, (2), 926-935.

46. Hess, B.; Bekker, H.; Berendsen, H. J.; Fraaije, J. G., LINCS: a linear constraint solver for molecular simulations. J. Comput. Chem. 1997, 18, (12), 1463-1472.

47. Essmann, U.; Perera, L.; Berkowitz, M. L.; Darden, T.; Lee, H.; Pedersen, L. G., A smooth particle mesh Ewald method. J. Chem. Phys. 1995, 103, (19), 8577-8593.

48. Hess, B., Determining the shear viscosity of model liquids from molecular dynamics simulations. J. Chem. Phys. 2002, 116, (1), 209-217.

49. Humphrey, W.; Dalke, A.; Schulten, K., VMD: visual molecular dynamics. J. Mol. Graphics 1996, 14, (1), 33-38.

50. Lehtinen, J.; Magarkar, A.; Stepniewski, M.; Hakola, S.; Bergman, M.; Róg, T.; Yliperttula, M.; Urtti, A.; Bunker, A., Analysis of cause of failure of new targeting peptide in PEGylated liposome: molecular modeling as rational design tool for nanomedicine. Eur. J. Pharm. Sci. 2012, 46, (3), 121-130.

51. Greenfield, N. J., Using circular dichroism collected as a function of temperature to determine the thermodynamics of protein unfolding and binding interactions. Nat. Protoc. 2006, 1, (6), 2527-2535.

52. Kelly, S. M.; Jess, T. J.; Price, N. C., How to study proteins by circular dichroism. Biochim. Biophys. Acta, Proteins Proteomics 2005, 1751, (2), 119-139.

53. Bolder, S. G.; Sagis, L. M.; Venema, P.; van der Linden, E., Thioflavin T and birefringence assays to determine the conversion of proteins into fibrils. Langmuir 2007, 23, (8), 4144-4147.

54. Hawe, A.; Sutter, M.; Jiskoot, W., Extrinsic fluorescent dyes as tools for protein characterization. Pharm. Res. 2008, 25, (7), 1487-1499.

55. Batzli, K. M.; Love, B. J., Agitation of amyloid proteins to speed aggregation measured by ThT fluorescence: a call for standardization. Mater. Sci. Eng. C Mater. Biol. Appl. 2015, 48, 359-364.

56. Lee, C.-C.; Nayak, A.; Sethuraman, A.; Belfort, G.; McRae, G. J., A three-stage kinetic model of amyloid fibrillation. Biophys. J. 2007, 92, (10), 3448-3458. 
57. Giddings, J. C.; Yang, F.; Myers, M. N., Flow-field-flow fractionation: a versatile new separation method. Science 1976, 193, (4259), 1244-1245.

58. Messaud, F. A.; Sanderson, R. D.; Runyon, J. R.; Otte, T.; Pasch, H.; Williams, S. K. R., An overview on field-flow fractionation techniques and their applications in the separation and characterization of polymers. Prog. Polym. Sci. 2009, 34, (4), 351-368.

59. Engert, J.; Mathaes, R.; Winter, G., Asymmetrical Flow Field Flow Fractionation: A Useful Tool for the Separation of Protein Pharmaceuticals and Particulate Systems. In Analytical Techniques in the Pharmaceutical Sciences, Springer: 2016; pp 467-488.

60. $\quad$ Fry, D. C.; Madison, V. S.; Bolin, D. R.; Greeley, D. N.; Toome, V.; Wegrzynski, B. B., Solution structure of an analog of vasoactive intestinal peptide as determined by twodimensional NMR and circular dichroism spectroscopies and constrained molecular dynamics. Biochemistry 1989, 28, (6), 2399-2409.

61. Wray, V.; Nokihara, K.; Naruse, S., Solution Structure Comparison of the VIP/PACAP Family of Peptides by NMR Spectroscopy. Ann. N. Y. Acad. Sci. 1998, 865, (1), 37-44.

62. Coelho-Cerqueira, E.; Pinheiro, A. S.; Follmer, C., Pitfalls associated with the use of Thioflavin-T to monitor anti-fibrillogenic activity. Bioorg. Med. Chem. Lett. 2014, 24, (14), 3194-3198.

63. Morel, B.; Varela, L.; Azuaga, A. I.; Conejero-Lara, F., Environmental conditions affect the kinetics of nucleation of amyloid fibrils and determine their morphology. Biophys. J. 2010, 99, (11), 3801-3810.

64. Ruzafa, D.; Morel, B.; Varela, L.; Azuaga, A. I.; Conejero-Lara, F., Characterization of oligomers of heterogeneous size as precursors of amyloid fibril nucleation of an $\mathrm{SH} 3$ domain: an experimental kinetics study. PLoS One 2012, 7, (11), e49690.

65. Hirotsu, T.; Higashi, T.; Abu Hashim, I. I.; Misumi, S.; Wada, K.; Motoyama, K.; Arima, H., Self-Assembly PEGylation Retaining Activity (SPRA) Technology via a HostGuest Interaction Surpassing Conventional PEGylation Methods of Proteins. Mol. Pharmaceutics 2017, 14, (2), 368-376.

66. Gubeli, R. J.; Sonzini, S.; Podmore, A.; Ravn, P.; Scherman, O. A.; van der Walle, C. F., Selective, non-covalent conjugation of synthetic peptides with recombinant proteins mediated by host-guest chemistry. Chem. Commun. (Cambridge, U. K.) 2016, 52, (22), 42354238 . 


\section{FOR TABLE OF CONTENTS USE ONLY}

Control of peptide aggregation and fibrillation by physical PEGylation

Elena Ambrosio ${ }^{a}$, Adrian Podmore ${ }^{b}$, Ana L Gomes dos Santos ${ }^{b}$, Aniket Magarkar $^{c}$, Alex Bunker $^{c}$, Paolo Caliceti ${ }^{a}$, Francesca Mastrotto $^{a}$, Christopher F. van der Walle ${ }^{b}$, Stefano Salmaso $a^{*}$

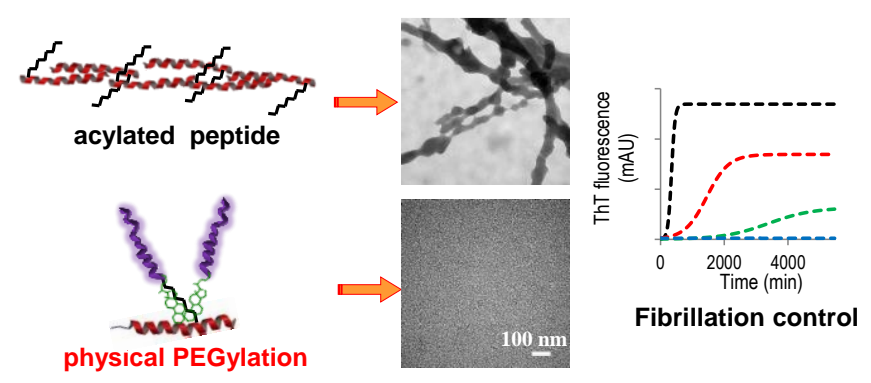

